Proceedings

\title{
Biorefinery Combining HTL and FT to Convert Wet and Solid Organic, Industrial Wastes into 2nd Generation Biofuels with Highest Efficiency: Heat-to-Fuel ${ }^{+}$
}

\author{
Tatiana Loureiro * and Raymond Sterling \\ R2M Solution, Calle Cervera 59, 1 D, 28033 Madrid, Spain; raymond.sterling@r2msolution.com \\ * Correspondence: tatiana.loureiro@r2msolution.com; Tel.: +34-622-738-061 \\ + Presented at Sustainable Places 2018 (SP2018), Aix-les Bains, France, 27-29 June 2018.
}

Published: 28 August 2018

\begin{abstract}
Heat-to-Fuel is a 48 months Horizon 2020 project which main objective is to deliver the next generation of biofuel production technologies supporting the de-carbonisation of the transportation sector by integrating its novel technologies together with innovative activities on design, modelling, development of hardware and processes, testing and life cycle analysis of a fully integrated system.
\end{abstract}

Keywords: biofuel; decarbonisation; transportation sector

\section{Introduction}

Heat-to-Fuel [1] is a Horizon 2020 EU-funded project carried out by 14 partners from across Europe that aims to deliver the next generation of biofuel production technologies supporting the decarbonisation of the transportation sector.

In numbers, Heat-to-fuel aims to: (1) Deliver cost-competitive technologies achieving biofuel prices below $€ 1$ per litre. This is achieved by a $20 \%$ cost reduction in the biofuel production processes; (2) Increase the quality of the biofuel resulting in $5 \%$ life-cycle green-house gases emissions reduction; (3) Contribute to delivering goals of EU's energy security by increasing the share of local resources used for producing energy, and thus reducing EU's dependency of energy's imports; (4) Support local economies by generating 80-100 direct and 250 indirect jobs each time a new Heat-to-Fuel biorefinery is built; (5) Prove the technological feasibility and economic worthiness of the concept acting as a catalyst of future industrial units.

These overarching objectives will be achieved thanks to the integration of novel technologies in Heat-to-Fuel together with innovative activities on design, modelling, development of hardware and processes, testing and life cycle analysis of a fully integrated system.

At the end of the project, the know-how acquired will allow scalability at a demonstration level before commercialisation, representative of the next generations of sustainable biofuel technologies.

The project, coordinated by the Austrian institution Güssing Energy Technologies, started in September 2017 and will last four years. 


\section{About the Project}

\subsection{Why Heat-to-Fuel?}

Transportation fuels corresponded in 2013 to 31.6\% of the final energy consumption in Europe. The source of this energy depends to a large extent on fossil fuels imports. Diesel and kerosene represent, and will remain, two major fuels for heavy trucks and air transportation sectors, respectively. Indeed, the energy density of both fuels, about $35-38 \mathrm{MJ} / \mathrm{L}$, is unparalleled by other alternative solutions such as batteries, hydrogen, methane and DME. Decarbonised production of additive substitutes for fuels and diesel and kerosene (biofuels) as alternative to fossil fuels becomes relevant for reducing carbon emissions of both transport sectors.

Europe should grasp the opportunity and gain its leading role in providing efficient technologies and processes for decarbonised fuels for the transport sector of heavy trucks and aviation. The achievement of this challenge must be conducted through a synergic collaboration between universities, R\&D institutes, and industry. In that perspective, Heat-to-Fuel will investigate and validate an advanced concept integrating dry and wet biomass residues processing, thus exploiting the huge potential of Carbon conversion efficiency improvement arising from this configuration.

Dry biomass and organic waste conversion through gasification routes is characterized by large heat excess, which can be conveniently exploited by wet biomass and waste conversion routes. The combination of those routes is embedded within Heat-to-Fuel spirit, aiming at reaching a carbon conversion efficiency of $50 \%$, and being able to radically improve current targets of organic waste exploitation for biofuels production at the large scale.

This overarching objective will be achieved thanks to complementary activities on design, modelling, development of hardware \& processes, testing and life cycle analysis of a fully integrated Heat-to-Fuel system, representative of next generations of sustainable biofuels technologies [2] (process of the biofuel in Figure 1).

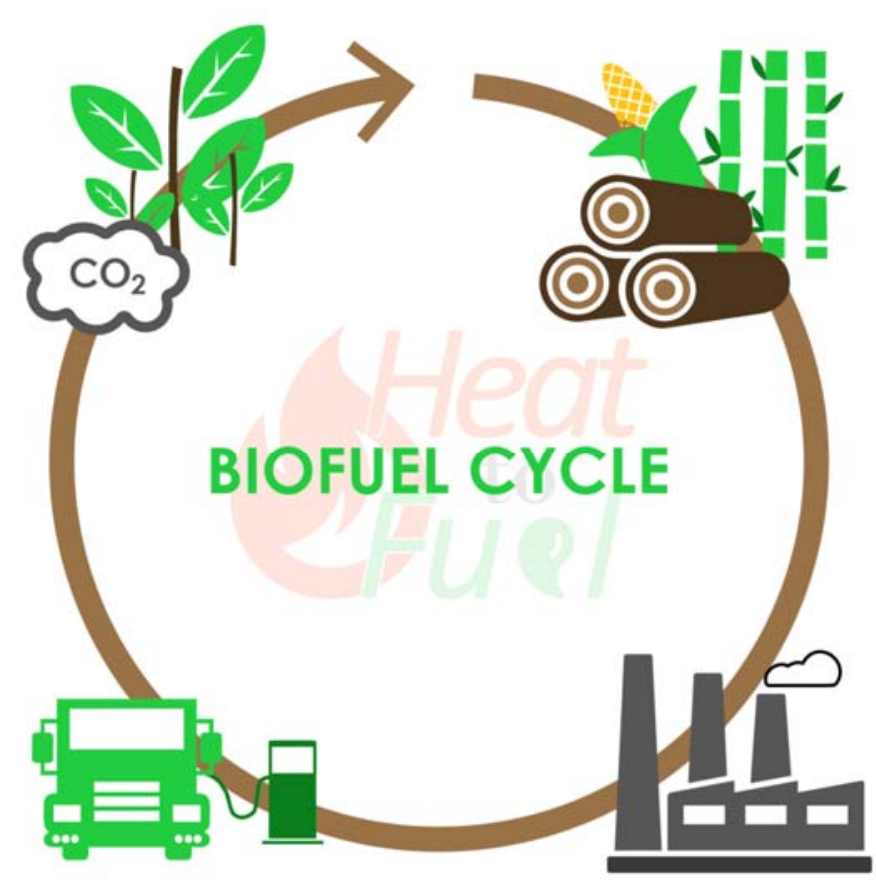

Figure 1. Biofuel cycle in Heat-to-Fuel.

\subsection{What Is It?}

Heat-to-Fuel is a Horizon 2020 EU-funded project carried out by 14 partners from across Europe that aims to deliver the next generation of biofuel production technologies supporting the decarbonisation of the transportation sector. 
Heat-to-Fuel partners possess over 100 years of combined sectorial expertise and experience in the production of biofuels, and they'll bring into the project the leading-edge demonstration facilities based on key industry and academic partners.

Transportation corresponded to 31.6\% of Europe's final energy consumption in 2013. The source of this energy depends to a large extent on fossil fuels import, being diesel and kerosene the two major fuels for heavy trucks and air transportation. Thus, decarbonised production diesel and kerosene as an alternative to fossil fuels becomes relevant for reducing carbon emissions in the sector. Heat-to-Fuel will spearhead EU's research in grasping the opportunity to provide efficient technologies and processes for decarbonised fuels for the transportation sector (Figure 2).
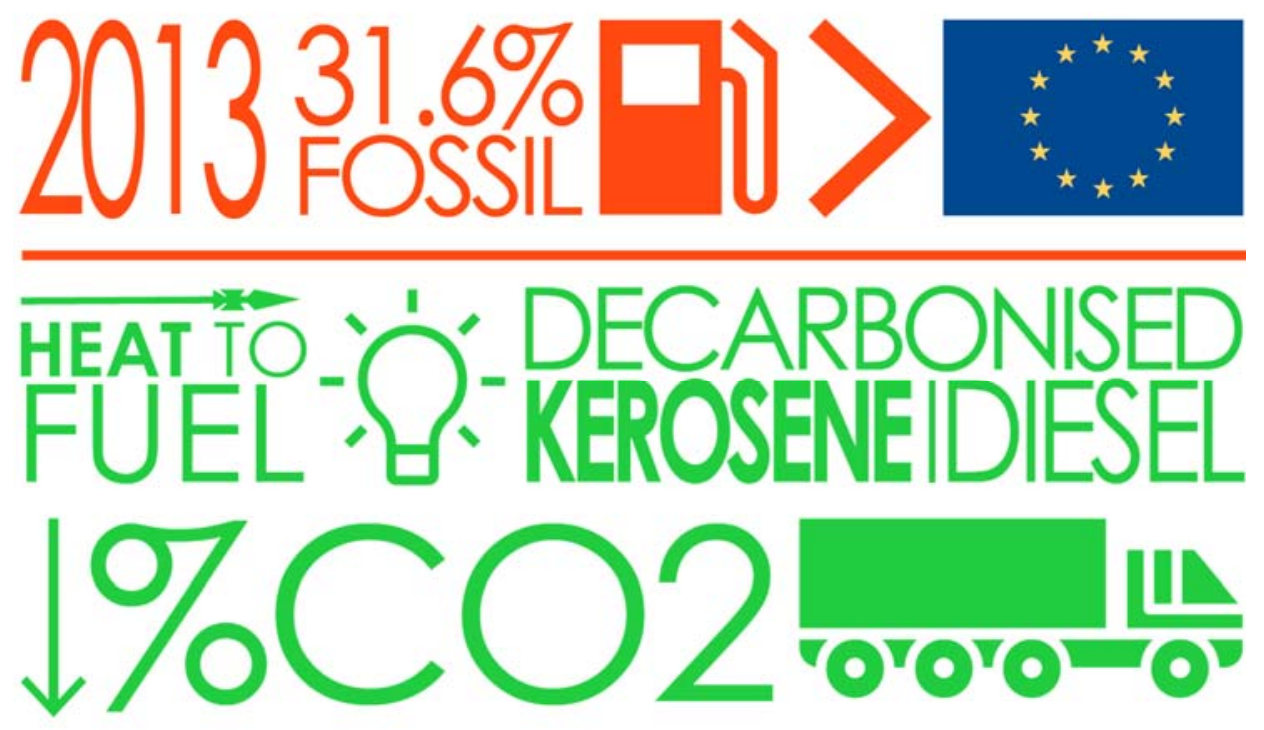

Figure 2. Aim of Heat-to-Fuel.

\subsection{Objectives}

In numbers, Heat-to-fuel aims to:

- Deliver cost-competitive technologies achieving biofuel prices below $€ 1$ per litre. This is achieved by a $20 \%$ cost reduction in the biofuel production processes;

- Increase the quality of the biofuel resulting in 5\% life-cycle green-house gases emissions reduction;

- Contribute to delivering goals of EU's energy security by increasing the share of local resources used for producing energy, and thus reducing EU's dependency of energy's imports;

- Support local economies by generating 80-100 direct and 250 indirect jobs each time a new Heatto-Fuel biorefinery is built;

- Prove the technological feasibility and economic worthiness of the concept acting as a catalyst of future industrial units.

These overarching objectives will be achieved thanks to the integration of novel technologies in Heat-to-Fuel together with innovative activities on design, modelling, development of hardware and processes, testing and life cycle analysis of a fully integrated system.

At the end of the project, the know-how acquired will allow scalability at a demonstration level before commercialisation, representative of the next generations of sustainable biofuel technologies, as illustrated in Figure 3. 

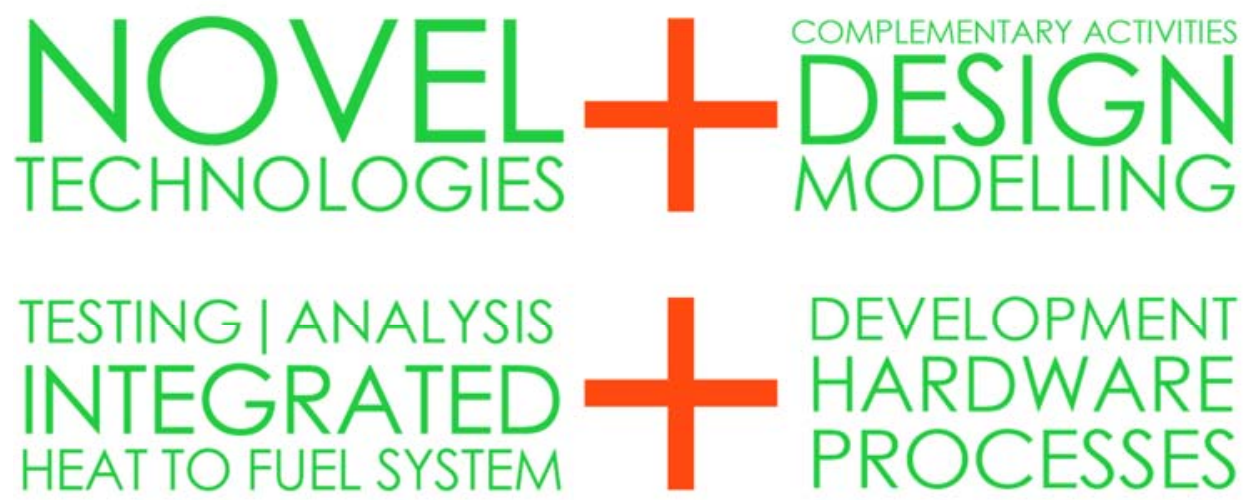
REPRESENTATIVE OF NEXT GENERATIONS OF SUSTAINABLE BIOFUELS TECHNOLOGIES

At the end of the project, the technology will be market ready in around 7 years The know-how acquired will allow scalability at a demonstration level before commercialisation

Figure 3. Heat-to-Fuel results.

\subsection{Consortium}

The consortium comprises 14 entities from 7 EU countries: 6 industrial partners $(2$ technical SMEs, 2 technology transfer and risk analysis SMEs, and 2 large component manufacturing industries); one end user from the transportation sector; 5 RTD and 2 HEA organizations to research and develop cutting-edge technologies (Figure 4). The consortium combines skills and expertise, bringing to the project a wide range of experts working with transdisciplinary approaches to environmental and industrial processes challenges.

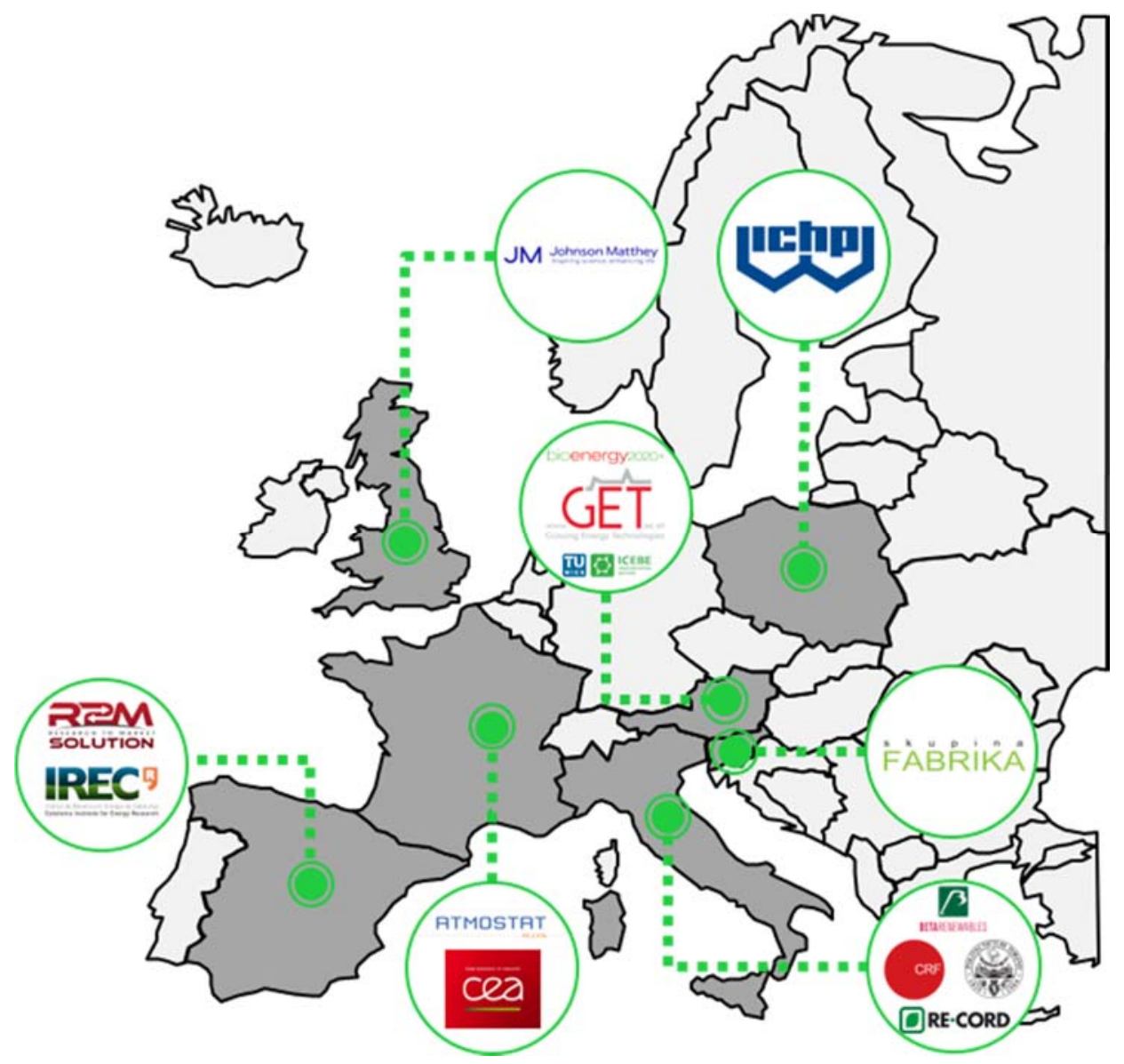

Figure 4. Map of Heat-to-Fuel partners. 
Funding: This research was funded by the European Union's Horizon 2020 research and innovation programme under Grant Agreement number 764675.

\section{References}

1. Heat-to-Fuel Page in CORDIS. Available online: https://cordis.europa.eu/project/rcn/211646_en.html (accessed on 26 July 2018).

2. Heat-to-Fuel Website. Available online: http://www.heattofuel.eu/ (accessed on 26 July 2018).

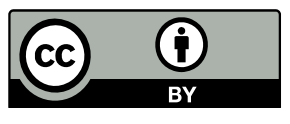

(C) 2018 by the authors. Licensee MDPI, Basel, Switzerland. This article is an open access article distributed under the terms and conditions of the Creative Commons Attribution (CC BY) license (http://creativecommons.org/licenses/by/4.0/). 